\title{
Involvement of the Ventral Tegmental Area in a Rodent Model of Post-Traumatic Stress Disorder
}

\author{
Nadia S Corral-Frias', Ryan P Lahood ${ }^{2}$, Kimberly E Edelman-Vogelsang ${ }^{3}$, Edward D French ${ }^{4}$ and \\ Jean-Marc Fellous*,5,6 \\ 'Graduate Interdisciplinary Program in Neuroscience, University of Arizona, Tucson, AZ, USA; ${ }^{2}$ Department of Molecular and \\ Cellular Biology, University of Arizona, Tucson, AZ, USA; ${ }^{3}$ Undergraduate Biology Research Program, Tucson, AZ, USA; \\ ${ }^{4}$ Department of Pharmacology, University of Arizona, Tucson, AZ, USA; ${ }^{5}$ Department of Psychology, Program in Applied Mathematics, \\ University of Arizona, Tucson, AZ, USA; ${ }^{6}$ Feinberg Foundation Visiting Faculty Program Fellow, Weizmann Institute, Rehovot, Israel
}

\begin{abstract}
Post-traumatic stress disorder (PTSD) is an anxiety disorder of considerable prevalence in individuals who have experienced a traumatic event. Studies of the neural substrate of this disorder have focused on the role of areas such as the hippocampus, the amygdala and the medial prefrontal cortex. We show that the ventral tegmental area (VTA), which directly modulates these areas, is part of this circuitry. Using a rat model of PTSD, we show that a brief but intense foot shock followed by three brief reminders can cause long-term behavioral changes as shown by anxiety-like, nociception, and touch-sensitivity tests. We show that an intraperitoneal injection of a dopamine (DA) antagonist or a bilateral inactivation of the VTA administered immediately before the traumatic event decrease the occurrence or intensity of these behavioral changes. Furthermore, we show that there is a significant decrease of baseline VTA dopaminergic but not GABAergic cell firing rates 2 weeks after trauma. Our data suggest that VTA DA neurons undergo long-term physiological changes after trauma and that this brain area is a crucial part of the circuits involved in PTSD symptomatology.

Neuropsychopharmacology (2013) 38, 350-363; doi:I0.1038/npp.20 I2.189; published online 26 September 20I2
\end{abstract}

Keywords: anxiety; dopamine; memory; addiction; emotion; nociception

\section{INTRODUCTION}

About $10 \%$ of individuals exposed to trauma will eventually suffer from post-traumatic stress disorder (PTSD) and will experience vivid nightmares, emotional and social withdrawal, irritability as well as other disruptive symptoms (Kessler et al, 1995). The impairments resulting from PTSD symptoms usually co-occur with other disorders, such as substance abuse and mood and anxiety disorders (Kessler et al, 2005; Kofoed et al, 1993; Najavits et al, 1997; Yehuda and LeDoux, 2007). Many PTSD patients also suffer from the development of stress-related medical conditions, such as hypertension, respiratory conditions, and chronic pain (Asmundson and Katz, 2009; Frayne et al, 2011).

The neural substrate of PTSD is complex and under active investigation. Various neural models of PTSD have established the role of the amygdala and its interactions with the medial prefrontal cortex and the hippocampus (Liberzon and Sripada, 2008; Rauch et al, 2006). These

\footnotetext{
*Correspondence: Dr J-M Fellous, Department of Psychology, Program in Applied Mathematics, University of Arizona, 1503 E University Building, P.O. Box 210068, Tucson 85721, AZ, USA, Tel: + I 520621 7447, Fax: + 520 621-9306, Email: fellous@email.arizona.edu Received 4 December 2011; revised 10 August 2012; accepted 15 August 2012
}

models are based on both animal and human data and show abnormal heightened responsiveness of the amygdala to threatening stimuli and inadequate regulation of the amygdala by the medial prefrontal cortex and the hippocampus (Garcia et al, 1999; Liberzon et al, 1999; Pissiota et al, 2002; Shin et al, 2004). This amygdala-centered view does not exclude the possibility that other areas may be involved. The ventral tegmental area (VTA), for example, has strong reciprocal interactions with these three areas (Fields et al, 2007). High comorbidity of PTSD with drug addiction (Kofoed et al, 1993; Najavits et al, 1997) and evidence showing deficits in the brain reward and reinforcement circuits in PTSD patients (Elman et al, 2009; Hopper et al, 2008) also suggest the involvement of dopaminergic systems such as the VTA. Finally, a recent case study suggested that psychostimulants, which enhance dopamine (DA) release, were effective at ameliorating symptoms in three combat-related PTSD patients (Houlihan, 2011).

The mesolimbic pathway has been shown to have an important role in fear conditioning (Inoue et al, 2000; Pezze and Feldon, 2004) and acute (Anstrom and Woodward, 2005; Valenti et al, 2011) and chronic (Moore et al, 2001) stress. Evidence for the involvement of the dopaminergic pathways in conditioned fear has been shown using systemic administration of D1 and D2 receptor antagonist and agonists. Research has shown that reduced DA (using 
systemic injections of a D1-receptor agonist) diminishes the freezing response elicited by conditioned fear (Inoue et al, 2000; Pezze and Feldon, 2004). Little research has been done to directly explore the role of dopaminergic systems, such as the VTA in animal models of PTSD. A recent study, however, identified the mesolimbic DA system as a key contributor to the resistance to social defeat in mice (Krishnan et al, 2007). This work showed that, as with human PTSD patients, vulnerable animals showed deficits in sensitivity to natural rewards (sucrose) and increases in drug-seeking behavior (cocaine).

Neurophysiologically, some studies showed that the mean firing rate of VTA DA neurons increased during an acute restraint paradigm and that the burst firing of a subset of DA neurons increased significantly compared with baseline (Anstrom and Woodward, 2005). This increase in burst firing could persist up to $24 \mathrm{~h}$ after a single exposure to stress. Others have shown that stressors increase the number of active dopaminergic neurons in VTA, when measured within $24 \mathrm{~h}$ of the last stress episode (Valenti et al, 2011). In contrast, other studies demonstrated that longterm (more than 17 days) chronic cold exposure yielded fewer spontaneously active VTA and medial substantia nigra neurons (Moore et al, 2001). However, in this study, the firing rates in the cells that remained active did not differ significantly from controls.

Taken altogether, these studies suggest that dopaminergic neurons of the VTA are affected by stress and respond differently depending on the type of stressor and the delay after which their activity is measured. Very little research has been conducted on the long-lasting effects of trauma on VTA cell activity. Here we study and validate a rodent model of PTSD, demonstrate the involvement of the dopaminergic system using systemic injections and demonstrate a specific role of the VTA by selective bilateral inactivation. We show the presence of trauma-related longterm electrophysiological changes in VTA DA cells. Preliminary results of this work were presented in abstract form (Corral-Frías et al, 2010).

\section{MATERIALS AND METHODS}

\section{Animals}

We used 63 male Sprague-Dawley rats weighing 300-400 g (33 behavioral, 16 injected intraperitoneally (i.p.) and 14 cannula-implanted). Animals were housed under a $12 \mathrm{~h}$ dark-light reversed cycle (lights off at 0900 hours). Behavioral testing was performed in the dark phase of the cycle. Animals had free access to food and water at all times. All the protocols used to complete this study were reviewed and approved by the Institutional Animal Care and Use Committee at the University of Arizona.

In order to assess the behavioral effects of stress, each rat was subjected to a battery of tests before and after the trauma-inducing procedure, so that each rat was its own control. The anxiety tests given up to 2 weeks after trauma were given in a contextual setting different from that of the trauma procedure. The timing of the experimental procedure is shown in Figure 1a and each test is discussed in details below or in Supplementary Material.

\section{Pre-Shock Tests}

Open field test. Rats were placed in the center of a circular black arena (diameter of $152.4 \mathrm{~cm}$, no obstacles) lined by a $30-\mathrm{cm}$ high peripheral wall in a dim room. The animals were allowed to freely move for 5 min before being returned to their home cage. The position of the animals was recorded automatically using a video tracker (20-30 frames per second). Animals underwent open field testing before shock and on day 16 after shock. The moving time and distance were calculated. This test was used to assess initial thigmotaxis. Thigmotaxis, or the tendency to remain close to walls, has been previously used as an index of anxiety in animals, as well as in humans, and is indicative of a general bias to safety-seeking phobic behavior (Kallai et al, 2007; Treit and Fundytus, 1988).

Nociception and touch-sensitivity tests. There is evidence that there are increases in pain sensitivity in PTSD patients (Asmundson et al, 2002). To assess whether increased nociception was present in our rat model, we tested for nociception and touch sensitivity using the tail flick test and the Von Frey test, respectively. The tests were administered the day before shock procedures and again on days 8 and 17 after the shock. See Supplementary Methods for a detailed description of these procedures.

\section{Trauma-Inducing Procedure}

The trauma procedure consisted of a single exposure to an inescapable foot shock (day 1) followed by three short reexposures to the shock chamber without foot shocks (situational reminders (SRs)) on days 3, 5 and 7 (Louvart et al, 2005; Pynoos et al, 1996). The shock apparatus was made of plexiglass $\left(54 \times 110 \times 40 \mathrm{~cm}^{3}\right.$ high $)$ and was subdivided into two equal-sized compartments separated by a guillotine door: a lighter first compartment and a darker second compartment (Figure 1bA and B). On the shock day, each rat was placed in the lighter compartment of the shock box. After a 3-min adaptation period, the guillotine door was opened and a bright light located in this first compartment was turned on for $20 \mathrm{sec}$. The door remained open until the animal entered the second compartment. After another 3-min adaptation period in the dark shock compartment, the rat received an inescapable continuous $2 \mathrm{~mA}$ foot shock for $10 \mathrm{sec}$. The sham group received the same treatment but the shock was not given. Both sham and shocked animals were reexposed to the context of the trauma (SRs) for 2 min once every 2 days for 3 days (Figure $1 \mathrm{bB}$ ). This was achieved by placing the animal in the lighter compartment with the guillotine door opened. The reexposure to the shock box was kept short to prevent extinction. The total time spent in the white compartment and number of crosses into the shock compartment were measured.

To investigate long-term behavioral sequelae, we tested anxiety behaviors 2 weeks after the shock. Animals were tested in three different apparati: the black and white box (also referred as light and dark box (Costall et al, 1989)), the elevated plus maze (Pellow, 1985; Walf and Frye, 2007), and the open field (Ohl, 2003). See Supplementary Methods for a detailed description of the anxiety-testing methods used. 


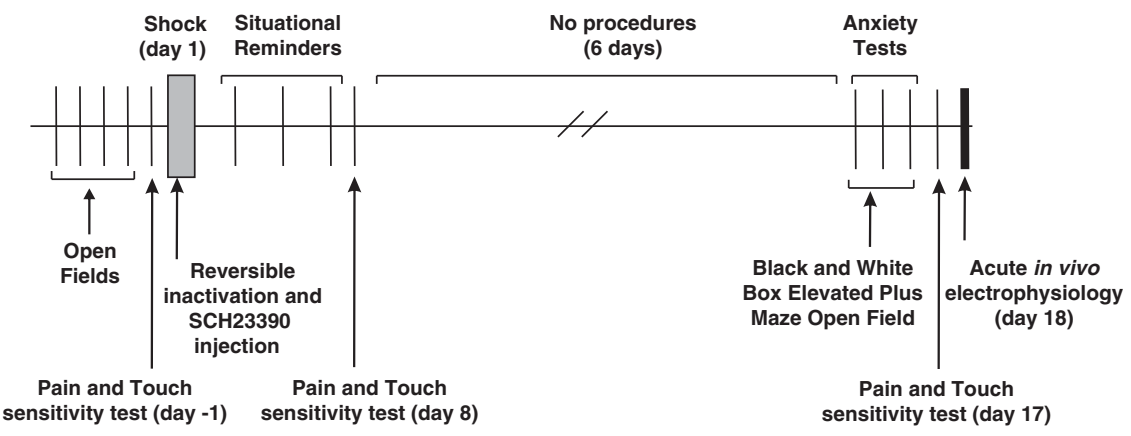

b
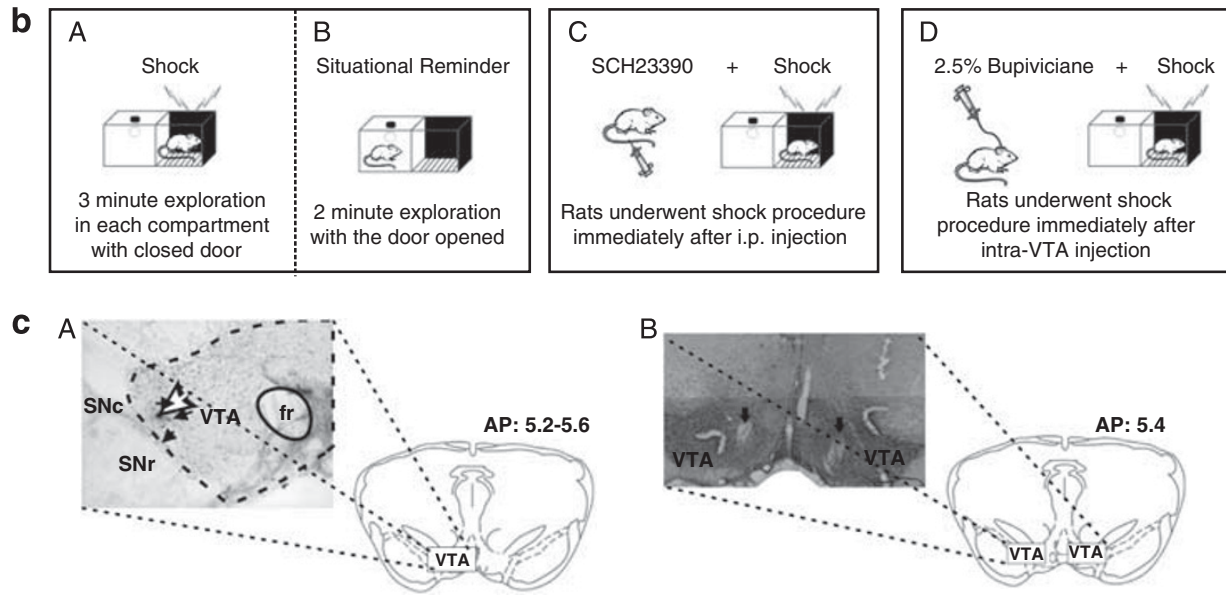

Figure I Behavioral protocols and histology. (a) General protocol. Animals underwent baseline measurements including 4 days of open fields and pain and touch-sensitivity tests. They were then exposed to a single inescapable foot shock (day I), followed by reexposures to the nonshock compartment of the shock cage (SRs, days 3, 5, and 7). To assess long-term behavioral sequelae, animals were evaluated for anxiety, pain, and touch sensitivity after 6 days of rest in their home cage. The experiments ended with acute recordings in the VTA. In two groups of animals, the dopaminergic system was interfered with, immediately before foot shock. (b) Trauma-inducing procedure. The trauma-inducing procedure consisted of a single 2-mA I0-s inescapable foot shock (A) followed by three SRs on 3 different days during which the animal was exposed to the safe compartment of the shock box for 2 min (B). A group of animal received a single i.p. injection of $\mathrm{DI}$-receptor antagonist ( $\mathrm{SCH} 23390)$ immediately before shock (C). Another group of animals received $2.5 \%$ bupivicaine hydrochloride or saline delivered in the VTA just before the foot shock (D). (c) Histology. Recordings were obtained from the peribrachial pigmented nucleus of the VTA and marked by ejection of Pontamine Sky Blue (white arrow, A). The location of the injection canulae was verified with tyrosine hydroxylase staining (black arrows, B).

\section{Intraperitoneal Injections of D1 Agonists}

A subset of animals was injected with the D1 antagonist SCH23390 (Sigma) prior to the shock procedure. Rats either received $0.1 \mathrm{mg} / \mathrm{kg}$ of $\mathrm{SCH} 23390$ (dissolved in $0.9 \%$ saline solution) or vehicle $(0.9 \%$ saline solution) only once, immediately before shock (Figure 1bC). All other phases of the experiments were identical.

\section{Intracerebral Cannulation and Injections}

A group of animals underwent cannulation surgery targeting the peribrachial pigmented nucleus in the VTA (NairRoberts et al, 2008). Rats were anesthetized with isoflurane and their body temperature was maintained at $37^{\circ} \mathrm{C}$ using a temperature-controlled heating pad. Two stainless steel guide cannulae (plastic one) were stereotaxically implanted bilaterally $5.4 \mathrm{~mm}$ posterior to bregma, $0.5 \mathrm{~mm}$ lateral to midline, and $7.5 \mathrm{~mm}$ below the skull. Five stainless steel microscrews were placed into the skull and dental cement was used to anchor the cannula guides to the screws and skull.
Rats either received bilateral injections of bupivacaine hydrochloride $(2.5 \%$ dissolved in $0.9 \%$ saline solution) or vehicle ( $0.9 \%$ saline solution) only once, on their shock day, immediately before shock (Figure $1 \mathrm{bD}$ ). This type of reversible local anesthetic has been previously used in the inactivation of VTA neurons (Mahmoodi et al, 2011; Moaddab et al, 2009; Seip and Morrell, 2009). All injections were done in awake rats with the internal cannulae extending $1 \mathrm{~mm}$ beyond the tip of the guide cannula and were performed using a microliter Hamilton syringe (Hamilton, Reno, NV) attached to flexible polyethylene tubing. See Supplementary Methods for a detailed description of spread and mechanisms of action of bupivicaine.

\section{Acute In Vivo Electrophysiology}

After all behavioral tests were completed, chloral hydrate $(350 \mathrm{mg} / \mathrm{kg}$, i.p., 14 rats) was used for the induction and maintenance of anesthesia (Cao et al, 2010). Supplemental doses of anesthetic ( $45 \mathrm{mg} / \mathrm{kg}$ intravenous) were given when vibrassal movements became evident. Each animal was fitted with a tracheal breathing tube and a catheter was placed in a lateral tail vein for the intravenous 
injection of apomorphine. Using stereotaxic procedures, a small burr hole was drilled in the skull overlying the VTA (5.2-5.6 $\mathrm{mm}$ posterior to bregma and $0.5-1 \mathrm{~mm}$ lateral to the midline suture). Body temperature was maintained at $37-38{ }^{\circ} \mathrm{C}$ throughout the experiment by a temperaturecontrolled heating pad.

Action potentials were recorded by single-barrel glasscapillary electrodes that were pulled and broken back to a tip diameter of approximately $1 \mu \mathrm{m}$ and filled with a solution of $2 \%$ Pontamine Sky Blue dye in $0.5 \mathrm{M} \mathrm{Na}$ acetate. The impedance of the electrodes ranged $12-20 \mathrm{M} \Omega$. At the end of each recording session, a DC current $(10 \mu \mathrm{A}$ pulses $10 \mathrm{~s}$ on $/ 10 \mathrm{~s}$ off for $20-30 \mathrm{~min}$ ) was passed through the recording electrode in order to eject the dye, which allowed for the identification of the location of the recorded cells (Figure 1c).

\section{Spike Sorting}

Action potentials were isolated using Spike 2 (Cambridge Electronic Design, UK). Using custom-written Matlab code (Mathworks), the firing and action potential properties of VTA cells were determined. Putative DA and GABA neurons were defined by the mean firing rate as well as the shape of the extracellular spike waveform (Supplementary Material, Supplementary Figures S2-S4). The mean activity was calculated using 5-min time windows. A burst was defined by a minimum of three successive spikes having an initial interspike interval (ISI) $\leqslant 80 \mathrm{~ms}$ and ending with an ISI $>160 \mathrm{~ms}$ (Grace and Bunney, 1984). Cells were classified as putative dopaminergic on the basis of their firing rate and spike waveforms (Supplementary Figures S2-S4 and (Ungless and Grace, 2012)). See Supplementary Methods for a detailed description of VTA neuron classification.

\section{Statistical Analyses}

All statistical analyses were conducted using SigmaStat software (SYSTAT, San Jose, California). Statistics were performed using the Mann-Whitney nonparametric test (sham, shock groups) or using an analysis of variance (ANOVA) (two-way repeated measures ANOVA) with time (days 3, 5, and 7 for SRs or days 1, 8, and 16 for nociception and touch-sensitivity tests) as a between-factor. A significant difference was indicated by ${ }^{*} p<0.05$ or ${ }^{* *} p<0.01$.

\section{Localization of Recording Electrodes and Cannulae and Immunohistochemistry}

Each rat was perfused transcardially with $0.9 \%$ saline and fixed with $4 \%$ paraformaldehyde in $0.1 \mathrm{M}$ phosphate buffer. The brain was extracted and cryoprotected overnight in a $30 \%$ sucrose and $0.02 \%$ sodium azide solution. Coronal sections were cut into $50-\mu \mathrm{m}$ slices on a cryostat. The electrode tracts were localized and their position in VTA confirmed (Figure 1c). One out of three slices was stained with Cresyl Violet. Another third of the slices was processed for tyrosine hydroxylase. The primary antibody was a rabbit anti-tyrosine hydroxylase from Chemicon (1:10000 in PBS-Triton-X100 with 3\% normal goat serum), followed by a biotinylated secondary antibody (diluted 1:1000, biotinylated rabbit anti-goat, Invitrogen, Oregon). An avidin-biotin peroxidase enzyme complex was prepared and applied according to the manufacturer's instructions (Vectastain Elite ABC kit). Finally, sections were incubated for $5 \mathrm{~min}$ in a $\mathrm{DAB} /$ hydrogen peroxide substrate solution (Sigma-Aldrich). Sections were mounted with cytoseal (Stephens Scientific) and coverslipped.

\section{RESULTS}

\section{Validation of The Rat Model of PTSD}

SRs. In order to mimic the conditions in which humans experience the most traumatic events (most PTSD patients are reexposed to the context of the trauma), rats underwent three short SRs (Pynoos et al, 1996). On days 3, 5, and 7, animals were placed in the nonshock (safe, light) compartment of the shock cage with the guillotine door opened and the total amount of time spent in each compartment was measured. Animals in the shock group avoided the black compartment in which the trauma procedure was induced, whereas animals in the sham group spent about a third of the time in the shock compartment (Figure 2a, two-way
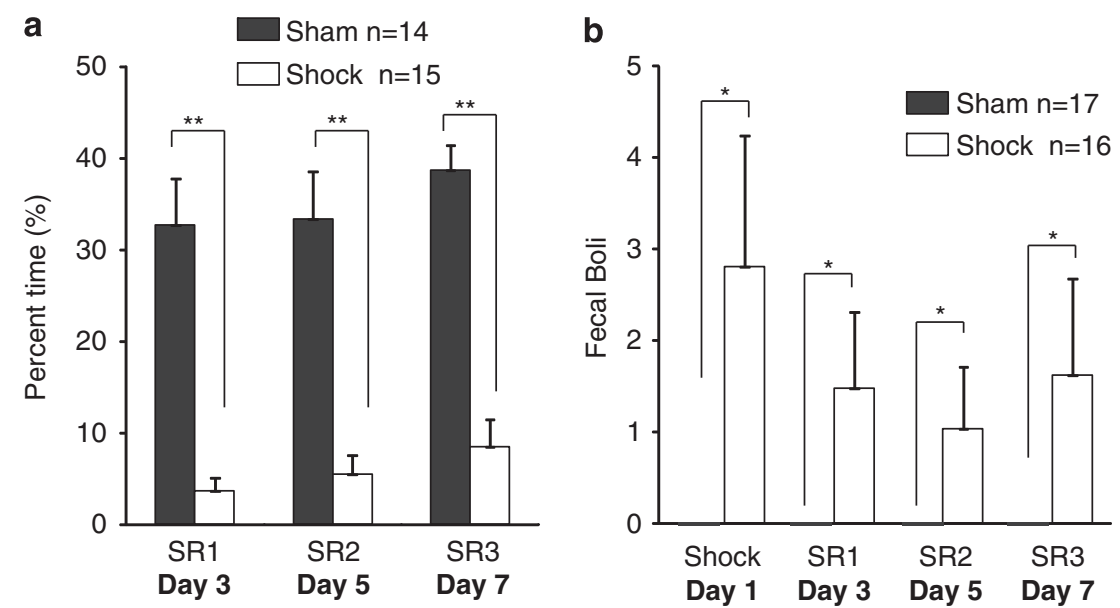

Figure 2 A single inescapable foot shock increases avoidance and excretion of fecal boli. (a) Percent time in shock compartment. Fraction of time spent in the shock compartment during SRs. (b) Fecal boli count. Number of fecal boli during shock and SRs. All error bars are SE (two-way repeated measures ANOVA and Mann-Whitney rank-sum test, $*^{*} p<0.01$, $\left.{ }^{*} p<0.05\right)$. 
repeated measures ANOVA, $p<0.01$ ). The fraction of time spent in the shock compartment did not differ significantly throughout the three exposures in either group. A bolus count was also conducted and the animals exposed to the trauma had a significantly higher count than their control counterparts (Figure 2b None of the sham animals excreted). These results demonstrated that animals that received the foot shock showed high avoidance of the trauma chamber up to 7 days after being shocked. In the following, the trauma-inducing procedure refers to the shock day and the three SRs.

\section{Anxiety Tests}

One of the main criteria for a valid PTSD animal model is to have long-lasting behavioral effects in response to a brief stressor (Siegmund and Wotjak, 2006; Stam, 2007; Yehuda and Antelman, 1993). To investigate long-term behavioral sequelae, we tested anxiety behaviors 2 weeks after the foot shock, using the black and white box, the elevated plus maze, and the open field tests. The black and white box is a well validated anxiety test in which more anxious animals spend less time in the white compartment, and have decreased general ambulation including decreased crosses back to the white compartment (Chaouloff et al, 1997; Costall et al, 1989; Louvart et al, 2005). The elevated plus maze is also used to assess the general level of anxiety of the animals in an environment entirely different from that of the trauma (Pellow et al, 1985). The open field test is used to assess the general level of anxiety (expressed by thigmotaxis) (Ennaceur et al, 2006).

Black and white box. On day 14 after the shock day, animals were tested in the black and white box and the latency to escape the white compartment, total time in the white compartment, and total number of white compartment reentries were measured. The mean latency to escape from the white compartment was $6.93 \mathrm{~s}$ for the sham group and the mean total time spent in the white compartment was $49.11 \mathrm{~s}(n=17)$. The animals that experienced the electrical foot shock had significantly longer latencies to escape (Figure 3a, average $15.13 \mathrm{~s}, n=17$, Mann-Whitney rank-sum test, $p<0.05$ ), possibly reflecting the fact that although different, the black and white box may be reminiscent of the shock box. Shocked animals spent less

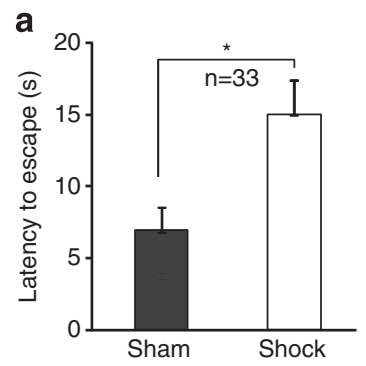

Black and White Box
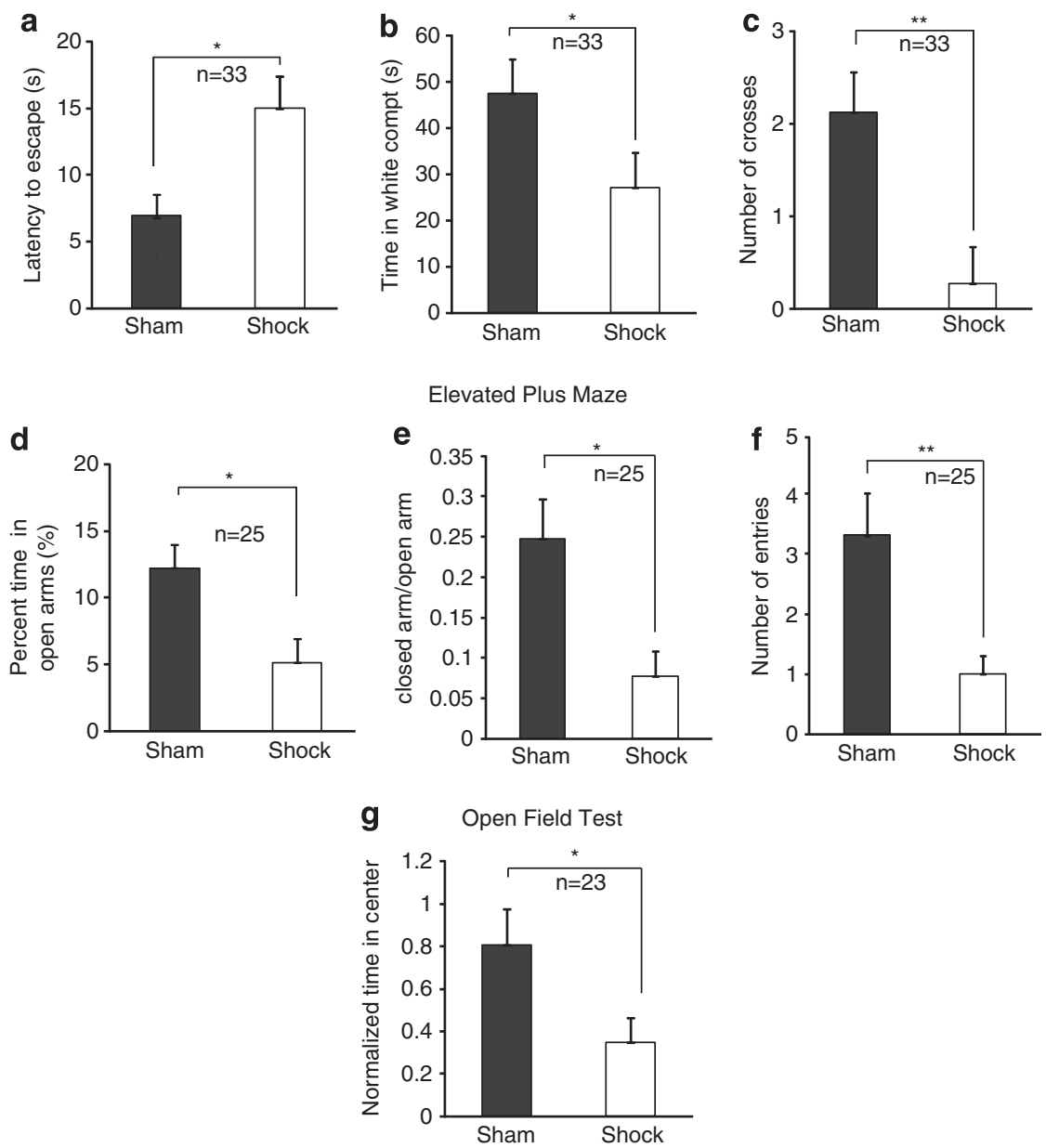

Figure 3 A single inescapable foot shock induces long-term behavioral changes in anxiety. Black and white box. (a) Latency to escape the white compartment (Day 14). (b) Total time spent in the white compartment. (c) Number of crosses back to white compartment. Elevated Plus Maze. (d) Time spent in the open arms. (e) Closed arm/open arm ratio. (f) Number of open arm entries. Open Field. (g) Normalized time in center. All error bars are SE. (two-way repeated measures ANOVA and Mann-Whitney rank-sum test $* * p<0.01, * p<0.05$ ). 

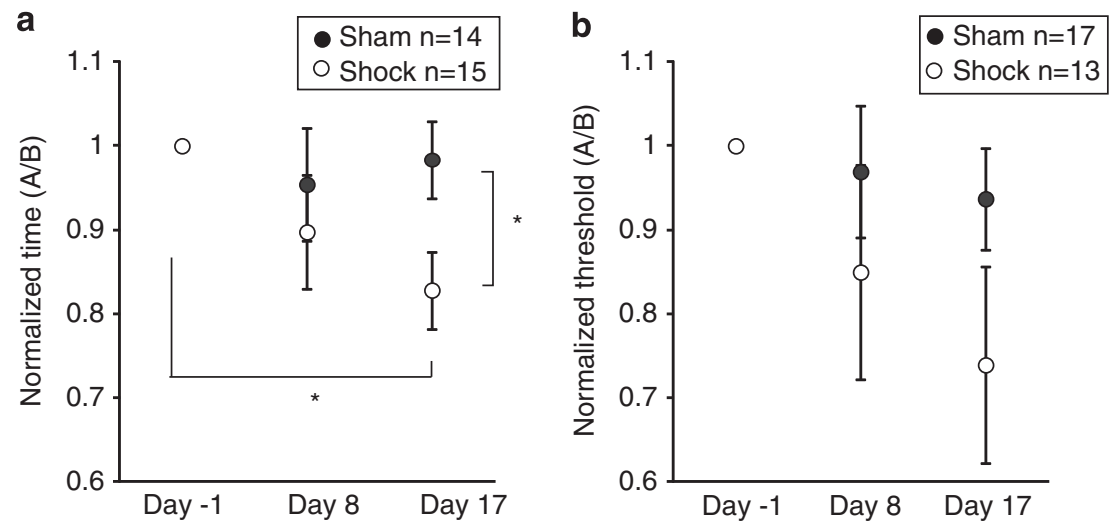

Figure 4 Trauma procedure induced changes in nociception sensitivity, but not in touch sensitivity. (a) Nociception. Normalized nociception measured by the tail flick test before foot shock (day I) and 8 and 17 days after foot shock. (b) Touch sensitivity. Normalized touch-sensitivity test assessed by the von Frey filament tests on the same days as in a (two-way repeated measures ANOVA, $* p<0.05$ ).

time in the white compartment than shams (Figure $3 b$, average $27.26 \mathrm{~s}, n=16$, Mann-Whitney rank-sum test, $p<0.05)$. The average number of white compartment reentries was significantly different for the shock and the sham groups (Figure $3 \mathrm{c}$ ).

Elevated plus maze. On day 15 after foot shock, rats were tested on the elevated plus maze. The total time and number of entries in the open and closed arms were recorded. The time spent in the open arms (Mann-Whitney rank-sum test, $p<0.05$, Figure $3 \mathrm{~d})$, the closed arm/open arm time ratio ((Mann-Whitney rank sum test, $p<0.05$, Figure $3 \mathrm{e})$, and the average number of open arm entries (Mann-Whitney rank sum test, $p<0.01$, Figure $3 \mathrm{f}$ ) were all significantly different between the shock and sham groups. These data demonstrate that the rats in the shock group expressed a higher level of anxiety than those in the sham group.

Open field test. The open field test was conducted 16 days after the foot shock. Because of the natural variability in thigmotactic behavior between rats, the time in the center was normalized on an animal-per-animal basis with respect to the times in the center obtained during the open field test performed before the trauma-inducing procedures. A significant difference in the time spent in the center of the field was observed between the two groups (Figure $3 \mathrm{~g}$, Mann-Whitney rank-sum test, $p<0.05$ ).

\section{Nociception and Touch Sensitivity}

One of the major health complaints expressed by PTSD patients is increased sensitivity to pain and other general disorders including chronic pain (Asmundson et al, 2002). To assess whether such an increase was present in our rat model, we tested for nociception and touch sensitivity using the tail flick test and the Von Frey test, respectively. We tested the animals on three occasions: the day before shock, and 8 and 17 days after shock. The measures were normalized on an animal-to-animal basis using data obtained before the shock procedure. On day 17, in the tail flick test, animals that underwent shock had a significantly shorter latency to remove their tail than those in the sham group as shown in Figure 4a (vertical comparison bracket, two-way repeated measures ANOVA, $p<0.05)$. The latency to remove the tail did not differ significantly throughout the three different test days in the sham group (two-way repeated measures ANOVA, black points, Figure 4a). However, there was a significant difference between days 1 and 17 in the shock group (Figure 4a, white points, horizontal comparison bracket). Interestingly, this increase in nociception did not appear to result from a change in touch sensitivity because there was no significant difference in touch sensitivity between the two groups, or across days (Figure $4 \mathrm{~b}$ ).

The results shown in the black and white box, elevated plus maze, and open fields, as well as the nociception test, demonstrate that the trauma-inducing procedure used here is capable of inducing anxiety-like behaviors that persist over time and result in a change in nociception akin to that observed in humans.

\section{Pre-shock D1-Antagonist Administration}

In order to characterize the role of DA in this PTSD animal model, we examined the effect of systemically blocking D1 receptors. A D1 antagonist (SCH23390) or saline was injected i.p. immediately before the shock procedures only once. The same behavioral procedures described in the Materials and methods were used in this group of rats.

SRs. On days 3, 5 and 7, i.p. injected animals were subjected to the SRs. Rats injected with SCH23390 spent about a tenth to a quarter of the total time in the shock compartment (SR1 13.76\%, SR2 7.55\%, and SR3 22.80\%). Rats that received vehicle injections had higher avoidance for the shock compartment than the SCH23390 animals (SR1 $5.94 \%$, SR2 $6.26 \%$, and SR3 7.18\%). A significant difference in the total percent time spent in the shock compartment was found on the last SR (Figure 5a, two-way repeated measures ANOVA, $p<0.05)$. Fecal boli counts were also conducted but did not reach statistical significance (Figure $5 b$ ).

\section{Anxiety Tests}

Black and white box. On day 14 after the shock day, SCH23390 and vehicle-injected animals were tested in the 

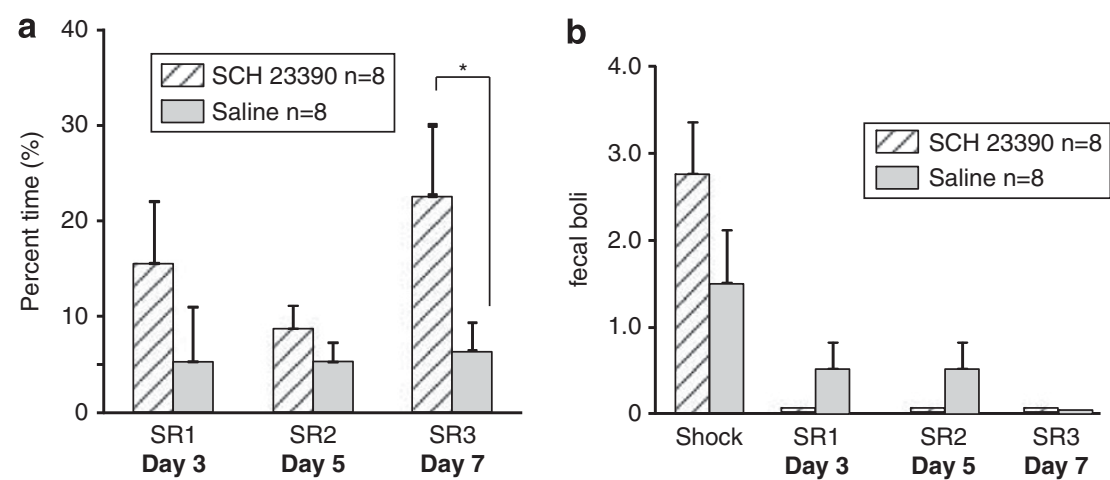

Figure 5 Behavior during SRs of DI-receptor antagonist injected animals. (a) Percent time in shock compartment. Fraction of time spent in the shock compartment during SRs. (b) Fecal boli count. Number of fecal boli excreted during shock and SRs. All graphs are means plus SE (two-way repeated measures ANOVA, $\left.{ }^{*} * p<0.01, * p<0.05\right)$.
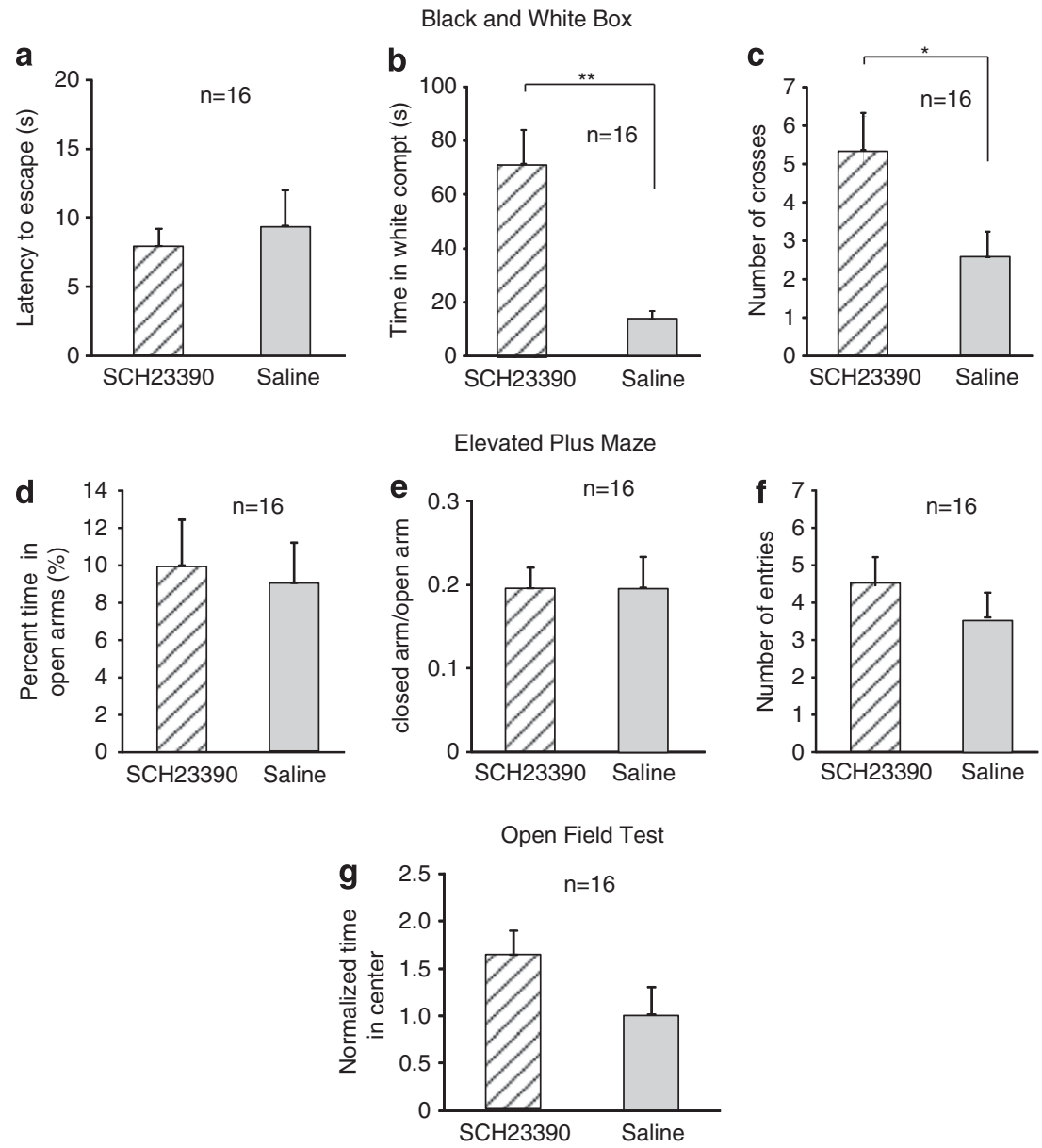

Figure 6 Behavioral changes in response to trauma are prevented by pre-shock DI-receptor antagonist injections. Black and white box. (a) Latency to escape the white compartment (Day 14). (b) Total time spent in the white compartment. (c) Number of crosses back to white compartment. Elevated plus maze. (d) Time spent in the open arms. (e) Closed arm/open arm ratio. ( $f$ ) Number of open arm entries. Open Field. (g) Normalized time in center. All error bars are SE. (two-way repeated measures ANOVA and Mann-Whitney rank-sum test, $* * * 0.01$, $* p<0.05$ ).

black and white box. The mean latency to escape from the white compartment was on average $9.81 \mathrm{~s}$ for the vehicle group and $7.51 \mathrm{~s}$ for the SCH23390-injected animals (Figure 6a). The mean total times spent in the white compartment were 12.96 and $69.54 \mathrm{~s}$ for the vehicle and D1receptor antagonist animals, respectively (Figure 6b, MannWhitney rank-sum test, $p<0.05$ ). The mean total number of crosses back to white compartment was 2.87 and 5.37 for the vehicle and $\mathrm{SCH} 23390$ animals, respectively (Figure 6c, Mann-Whitney rank-sum test, $p<0.05$ ).

Elevated plus maze. The total mean percent time spent in the open arms was not significantly different between the SCH23390-injected animals and the vehicle animals 

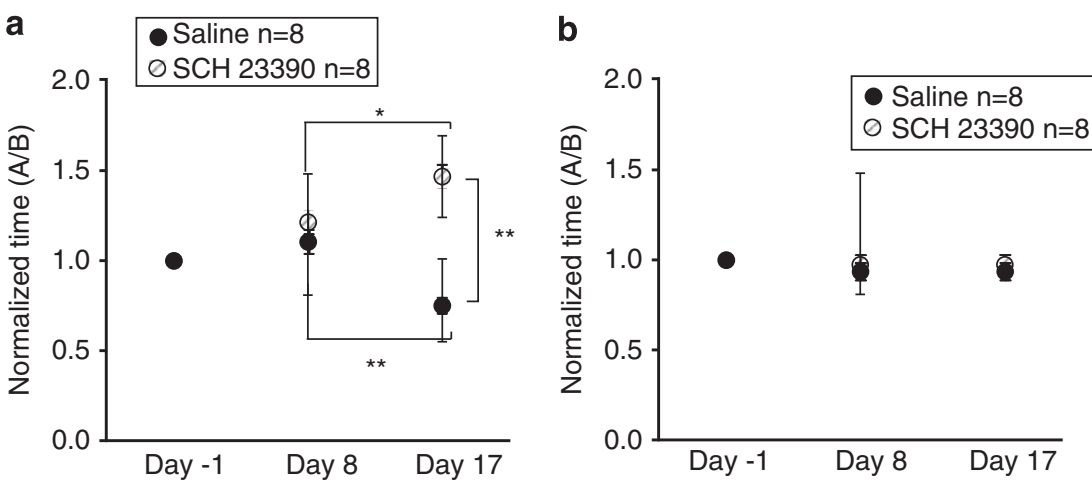

Figure 7 DI-receptor antagonist decreased nociception but not touch sensitivity. (a) Nociception. Normalized nociception measured by the tail flick test before foot shock (day I) and 8 and 17 days after foot shock. (b) Touch sensitivity. Normalized touch-sensitivity test assessed by the von Frey filament tests on the same days as in A (two-way repeated measures ANOVA, $* 0.05$ ).

(Figure 6d). The close arm/open arm time ratio (Figure 6e), as well as the number of open-arm entries (Figure 6f), was also not significantly different between the two groups. A significant difference was found, however, in the total mean percent time spent in the closed arms, with saline-injected animals spending significantly more time in the closed arms than SCH23390 animals $(64.1 \%$ and $57.1 \%$, respectively; Mann-Whitney rank-sum test, $p<0.05$, not shown).

Open field. The time in the center was normalized with respect to the time spent in the center before the shock was given. There was a trend indicating that the SCH23390 spent more time in the center of the field, but no significant difference was found (Figure $6 \mathrm{~g}$ ).

\section{Nociception and Touch Sensitivity}

As with the behavioral animals (Figure 4), the same animals were tested for nociception and touch sensitivity. There was a significant decrease in nociception between day 8 and 17 in the $\mathrm{SCH} 23390$ group (Figure 7a, black circles) and a significant increase in the vehicle group (Figure 7a, whitestripped circles). There were no significant differences in touch sensitivity in either group (Figure $7 b$ ).

\section{Pre-shock Reversible VTA Inactivation}

To test the hypothesis that the VTA is specifically involved in the long-term anxiety exhibited in our animal model, a separate group of animals was implanted bilaterally with cannulae targeted to the this area. Animals were subjected to the behavioral procedures described previously. All animals received microinjections of either bupivacaine hydrochloride or vehicle (saline) only once, immediately before the electrical foot shock on day 1 (Figure 1).

SRs. During the SRs, animals in the saline group avoided the shock compartment of the shock cage significantly more than the animals in the bupivacaine group (Figure 8a). The fraction of time spent in the shock compartment was larger for the bupivacaine group than for the saline group in all three SRs (two-way repeated measures ANOVA test, $p<0.05)$. Fecal boli counts were also conducted but no significant differences were found, although saline-treated rats tended to have a higher fecal boli count than the bupivacaine group (Figure $8 \mathrm{~b}$ ).

\section{Anxiety Tests}

Black and white box. Cannula-implanted animals were also tested in the black and white box. The latency to escape from the white compartment was not found to be significantly different between bupivacaine and saline groups, although a trend is observed (Figure 9a). The total time spent in the white compartment was, however, significantly different (Figure 9b, 22.85 vs $88.33 \mathrm{~s}$ for saline and bupivacaine animals, respectively). The number of crosses back into the white compartment was also significantly different between the two groups (Figure 9c, Mann-Whitney rank-sum test, $p<0.05)$.

Elevated plus maze. The total time spent in open arms was significantly different between the groups (Figure 9d, Mann-Whitney rank-sum test, $p<0.01$ ). The close arm/ open arm ratio was also found to be significantly different (Figure 9e, Mann-Whitney rank-sum test, $p<0.05$ ). The average number of open-arm entries in the saline and bupivacaine groups were significantly different as well (Figure 9f).

Open field test. The last anxiety test conducted in the cannula-implanted animals, 16 days after shock procedures, was the open field test. There was a trend for bupivacaine animals to spend more time in the center (ie, showing less thigmotaxis) than saline animals (Figure 9g).

Altogether, these results demonstrate that VTA inactivation had protective effects in this PTSD paradigm.

\section{Nociception and Touch Sensitivity}

In the tail flick test, animals that received saline intracranial injections had significantly shorter latencies to remove their tail on day 17 when compared with days 1 and 8 (increased nociception, gray points, Figure 10a). VTA-inactivated animals did not show significant changes in nociception (Figure 10a, black points). There was no significant change in touch sensitivity in either group of animals, although a small decreasing trend was apparent in the saline group (Figure 10b). 

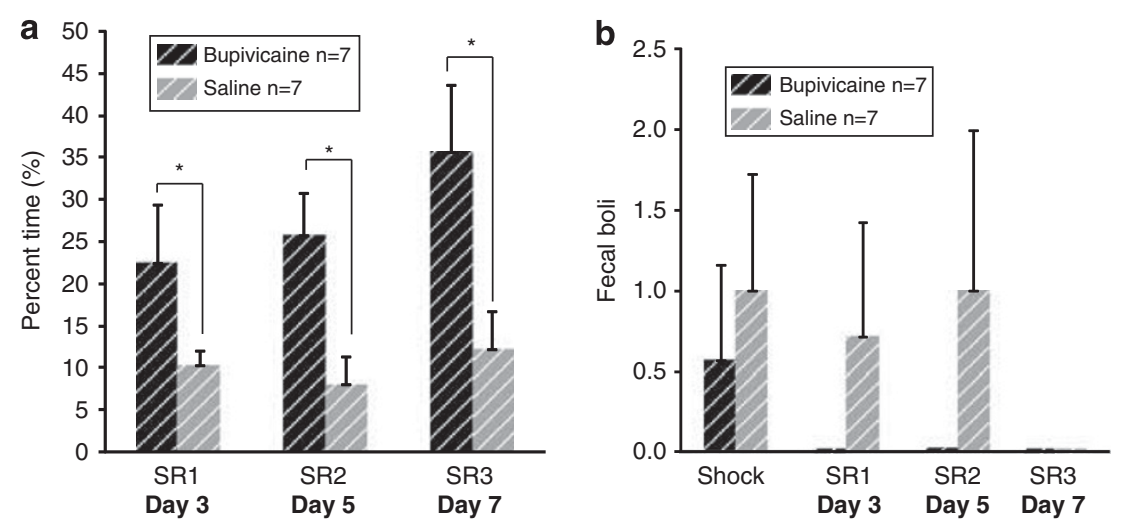

Figure 8 VTA inactivation decreased avoidance. (a) Percent time in shock compartment. Fraction of time spent in the shock compartment during SRs. (b) Fecal boli count. Number of fecal boli during shock and SRs. All error bars are SE (two-way repeated measures ANOVA and Mann-Whitney rank sum test, $\left.{ }^{*} p<0.05\right)$.

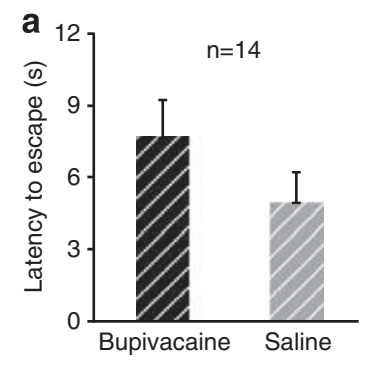

Black and White Box
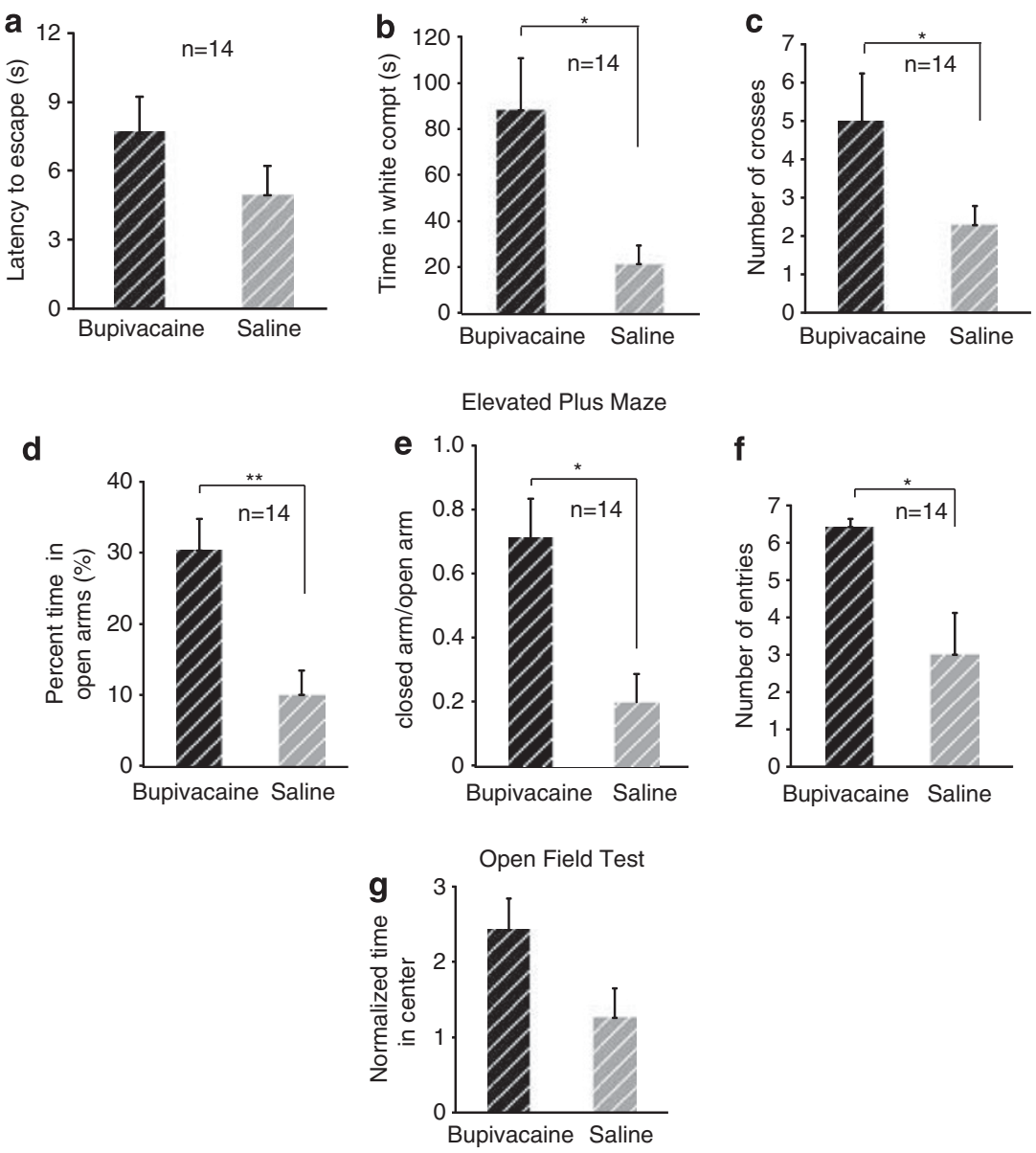

Figure 9 Behavioral changes in response to trauma are prevented by pre-shock VTA inactivation. Black and white box. (a) Latency to escape the white compartment (day 14). (b) Total time spent in the white compartment. (c) Number of crosses back to white compartment. Elevated plus maze. (d) Time spent in the open arms. (e) Closed arm/open arm ratio. (f) Number of open arm entries. Open Field. (g) Normalized time in center. All error bars are SE. (two-way repeated measures ANOVA and Mann-Whitney rank-sum test, $* * 2<0.0$ I, * $p<0.05$ ).

To control for possible analgesic effects of bupivicaine during the shock procedure, we assessed nociception in a separate group of rats. Using the Hargreaves test showed no difference in nociception before and after bupivacaine injections, excluding the possibility that bupivacaine animals were rendered insensitive to the foot shock by the intracranial injection (see Supplementary Figure S1). These results demonstrate that animals that underwent reversible inactivation of the VTA have less long-term increases in nociception than control. 

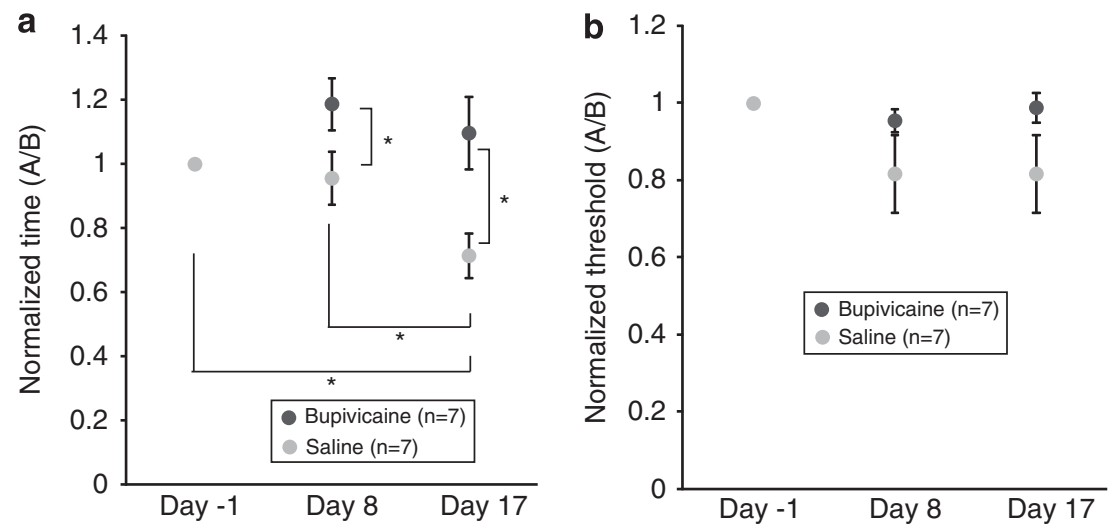

Figure 10 Increases in nociception were not present in animals with VTA inactivation. (a) Normalized nociception measured by the tail flick test before foot shock (day I) and 8 and 17 days after foot shock. (b) Touch sensitivity. Normalized touch-sensitivity test assessed by the von Frey filament tests on the same days as in A (two-way repeated measures ANOVA, ${ }^{*} p<0.05$ ).
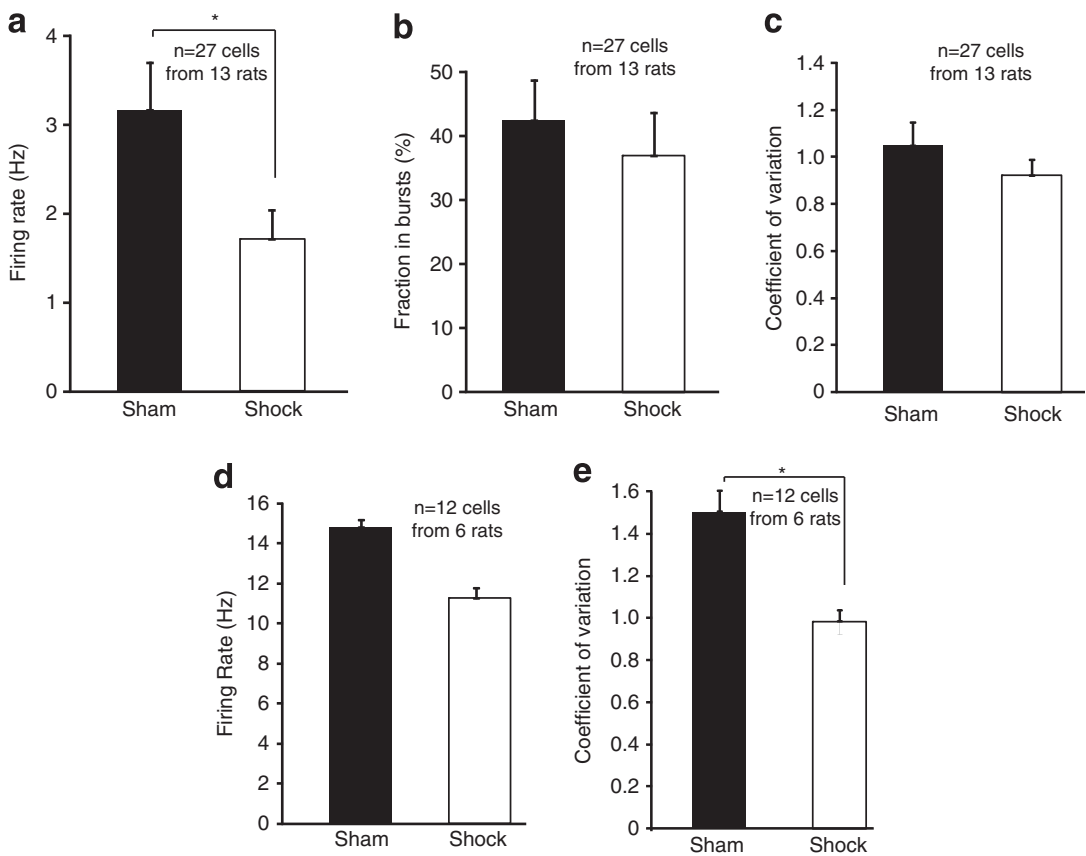

Figure I I Long-term (day I8) changes in VTA putative dopaminergic and GABAergic cell electrophysiology after trauma. (a) Mean firing rate for putative DA cells. (b) Fraction of action potentials in bursts in putative DA cells. (c) Coefficient of variation of putative DA cells. (d) Mean firing rate of putative GABA cells. (e) Coefficient of variation of putative GABA cells. All error bars are SE (Mann-Whitney rank-sum test, * $p<0.05$ ).

\section{Electrophysiology Experiments}

Following the last nociception and touch-sensitivity test, on day 18, VTA cells from the shock and sham animals were recorded. The mean baseline firing rate of putative VTA DA cells of shocked animals was significantly lower than that of control animals (Figure 11a).

The bursting mode in VTA cells is thought to be important to boost the gain of neural signaling of salient stimuli by enhancing transmitter release and dendritic depolarization (Cooper, 2002). There was no significant difference between the fraction of action potentials fired in bursts between the shock and sham groups (Figure 11b). The coefficient of variation measures the regularity of cell firing (CV close to zero is regular; CV close to 1 is nearPoisson). There was no significant difference between the shock and sham groups (Figure 11c).
The firing rates of putative GABAergic cells were also calculated. There was no significant difference between shock and sham group baseline firing rates (Figure 11d). However, there was a significant difference in the coefficient of variation between shock and sham group. GABAergic cells in the sham animals had a CV $>1$, reflecting irregular bursting patterns whereas the $\mathrm{CV}$ was near 1 in the shocked animals (Figure 11e).

\section{DISCUSSION}

The number of PTSD diagnoses is rapidly increasing. There is to this day no specific pharmacological treatment for this disorder, and most patients are given antidepressants or antipsychotics, mainly to treat their symptoms. Animal models of PTSD have the potential to provide insights into 
the etiology, course and possible novel treatments of this disease. A widely accepted family of animal models relies on the inescapable foot-shock paradigm. This type of animal model has demonstrated many symptomatic and physiological similarities with human PTSD (Stam, 2007). Animal models based on inescapable foot stocks have shown increases in anxiety (Louvart et al, 2005; Stam et al, 2002; Van Dijken et al, 1992), hypervigilance (object burying) (Langevin et al, 2010; Mikics et al, 2008), decreases in social interaction (Louvart et al, 2005), as well as increases in nociception (Geerse et al, 2006). The inescapable foot-shock paradigm is also a suitable model because the trauma that gives rise to PTSD, such as rape or combat-related injuries, often occurs without the control of the individual. An imperative criterion to be met for a valid PTSD model is that the behavioral sequelae persist over time. It has been shown that a brief intense inescapable foot shock together with subsequent SRs cause increased anxiety-like behavior and blunted corticosterone levels and that these effects remain up to 6 weeks after the traumatic event (Louvart et al, 2005; Pynoos et al, 1996). Consistent with previous animal models, we demonstrated here that a brief intense inescapable foot shock followed by SRs can cause long-term behavioral sequelae such as avoidance for the traumatic spatial context and increased anxiety (Figures 2 and 3 ). Furthermore, these long-term anxiety-like behaviors are accompanied by increases in nociception (Figure 4), a feature often noted in PTSD patients.

The study of the neural substrate of PTSD is best tackled using a multidisciplinary approach including medical, neuroscientific, and pharmacological studies. Most conceptual models investigating this neurocircuitry include the amygdala, the hippocampus, and the prefrontal cortex (Liberzon et al, 1999; Rauch et al, 2006). We present evidence for the involvement of the dopaminergic system by showing that injecting systemically a D1-receptor antagonist just before trauma decreases the appearance of avoidance and long-term anxiety behaviors in some of the tests conducted (Figures 5 and 6). We further show evidence for the involvement of the VTA by demonstrating that the long-term behavioral consequences induced by a traumatic event can be prevented if VTA cells are inactivated immediately before the event (Figures 8 and 9). This result assumes that bupivacaine inactivation in VTA does not have long-term consequences, as suggested by several studies in other brain areas (see Supplementary Material). Overall, the reduction in anxiety due to $\mathrm{SCH} 23390$ administration is less pronounced than that of VTA inactivation (compare Figures 6, 7, 9 and 10, respectively). This difference may be attributed to a number of factors including overall system-wide short-term compensation for SCH23390 D1 antagonism, the effect of SCH23390 on areas other than VTA, the dosage of the drug, the role of the intact D2 system, and the fact that bupivacaine inactivates all neurons in VTA, not just dopaminergic ones.

These findings are compatible with other studies that have indirectly implicated the VTA in PTSD. Others have, for example, suggested the involvement of the VTA in PTSD by observing high comorbidity with drug addiction (Kofoed et al., 1993; Najavits et al., 1997) and reduced reward sensitivity among PTSD patients (Elman et al, 2009; Hopper et al, 2008). Moreover, DA released from VTA cells has the potential to modulate the activity in areas important for the consolidation and retrieval of emotional memories, such as the hippocampus and the amygdala, as well as modulate areas essential for the extinction of memories such as medial prefrontal cortex (Fields et al, 2007). The VTA has also been shown to be an important factor in the nociception pathways (Becerra et al, 2001; Borsook et al, 2007; Saade et al, 1997). Altogether, this evidence strongly suggests that the VTA may have an important role in PTSD symptomatology.

In this study, we show that VTA DA cells in traumaexposed rats have lower baseline firing rates 18 days after the shock procedure when compared with sham rats (Figure 11a). This difference in firing rates may be due to an increase in intrinsic VTA GABAergic activity from a neural population not recorded here, an increase of external-VTA inhibitory inputs, and/or changes in intrinsic membrane excitability. Further experiments using optogenetic techniques (Tan et al, 2012) or simultaneous recordings in areas such as the basolateral nucleus of the amygdala, or the medial prefrontal cortex in vivo and work in vitro would be required to tease these possibilities apart. These changes in VTA DA cell electrophysiology can give rise to changes in baseline tonic DA levels in areas mediating emotional and cognitive processes and can lead to the inadequate responses to stress often seen in PTSD patients.

Given the heterogeneity of PTSD symptoms (hyperarousal, avoidance, and reexperiencing symptoms) and the medical (chronic pain, respiratory, and cardiac disorders) and psychiatric (other anxiety and mood disorders and substance abuse) consequences, it is likely that the neural substrate involved also varies heterogeneously from patient to patient. A possible explanation for the wide differences in relative severity of symptoms may reside in the deregulation of a brain region that has widespread connections to various areas involved in perception, learning, memory, and other cognitive and emotional functions. Compatible with other models (Liberzon and Sripada, 2008; Sigurdsson et al, 2007), we propose that the hippocampus processes contextual information related to the trauma (Payne et al, 2007; Payne et al, 2003) and that the medial prefrontal cortex regulates the degree to which the amygdala expresses emotional responses (Figure 12a). In our conceptual model, the VTA modulates the activity of these three areas and indirectly regulates emotional responses to the traumatic event both in the short term and in the long term.

We propose that the hyperresponsiveness of the amygdala to stress and the inadequate regulation of the medial prefrontal cortex and the hippocampus after trauma are in part due to a deregulation of the mesolimbic dopaminergic modulatory system (Figure 12b). We propose that traumatic stress increases VTA DA activity transiently to high levels, as has been observed in acute stress paradigms (Anstrom et al, 2009; Anstrom and Woodward, 2005; Brischoux et al, 2009; Morrow et al, 2000; Valenti et al, 2011). This increase of DA activity during a traumatic event has the shortterm consequence of enhancing the consolidation of the traumatic memory. This increase in consolidation may rely on well-established synaptic plasticity mechanisms, such as long-term potentiation and depression (LTP/LTD). 

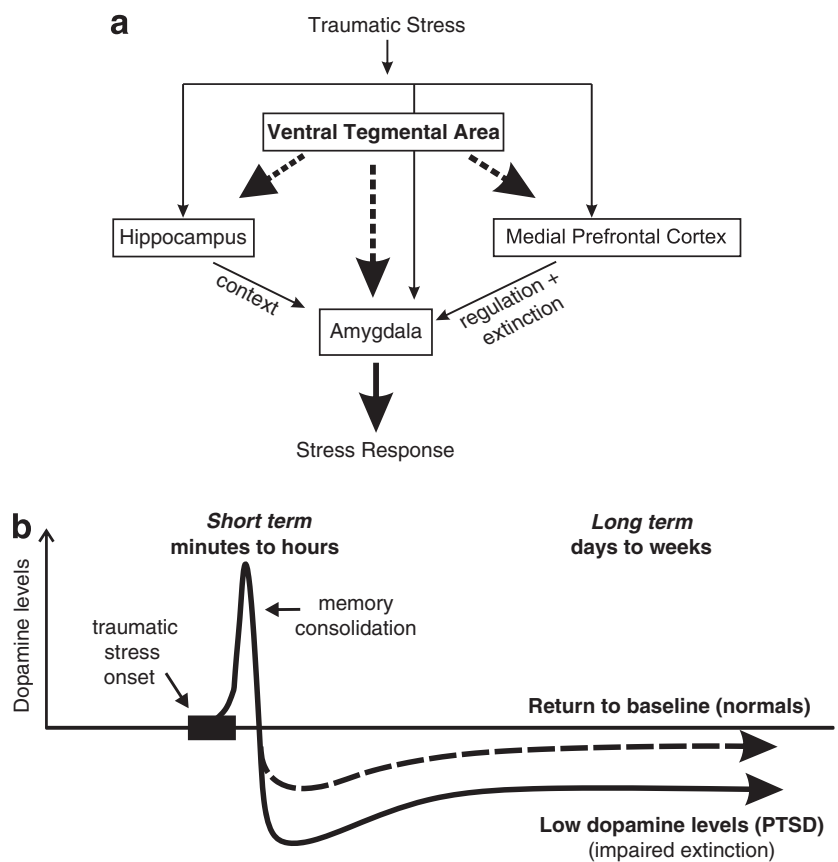

Figure 12 Conceptual model. (a) Neural circuitry involved in PTSD. DA released from VTA cells modulate the activity and synaptic plasticity in areas important for the consolidation and retrieval of emotional memories, such as the hippocampus and the amygdala. The VTA also projects to areas essential for the extinction of memories such as medial prefrontal cortex. (b) PTSD as mesolimbic deregulation. During and immediately after a traumatic event DA levels increase above baseline levels. This increase strengthens memory consolidation. The circuitry compensates for this increase by a large decrease below baseline. In most individuals, DA levels return to baseline. We propose that in a PTSD patient, the return to baseline does not occur, possibly preventing the extinction of traumatic memories.

Experiments in hippocampal slices show indeed that LTP in CA1 depends on the activation of DA receptors (Frey et al, 1990; Lisman et al, 2011; Lisman and Grace, 2005). Furthermore, evidence from behavioral experiments show that DA enhances learning (Morris et al, 2003). Finally, the increase of DA levels by administration of L-DOPAenhanced memory and COMT (enzyme that metabolizes DA) inhibitors also showed memory improvements in various tasks in human subjects (Apud et al, 2007). We then propose that this short-term increase of DA activity may be followed by a compensatory mechanism that aims at returning DA to normal levels. In most subjects, after perhaps a transient period of hypodopaminergic activity, the DA firing rates return to normal (dashed curve, Figure 12b). In a small fraction of subjects, however, the down stroke of the compensatory mechanism may cross a phenomenological nonrecovery threshold such that the return to baseline DA levels is prevented or significantly slowed down (continuous curve, Figure 12b). The firing rate of DA cells remains lowered (hypoactive), as we showed here in rats and compatible with other studies in which lower dopaminergic activity was measured over 2 weeks after trauma onset (Moore et al, 2001). In this group of subjects, traumatic stress decreases DA levels in the long term and this decrease would cause a failure to reconsolidate and failures to extinguish traumatic memories, an active process that requires LTP/LTD mechanisms. The subjects would develop PTSD. This theory is consistent with pharmacological experiments showing that brain infusions of D4 antagonists into prefrontal cortex impair fearconditioning extinction (Pfeiffer and Fendt, 2006) and by evidence showing decreased DA release in PFC (Goto et al, 2007; Gresch et al, 1994). Moreover, it has been shown that prolonged stress impairs LTP induction (Goto and Grace, 2006). If DA activity is prevented from increasing at the time of trauma, as in our inactivation experiments, no upstroke and compensatory down stroke occur, and DA levels are unaffected. Further evidence for the long-term hyporesponsiveness of the mesolimbic pathway is suggested by successful treatment of PTSD patients with psychostimulants (Houlihan, 2011), which enhance DA release in areas such as the prefrontal cortex and may alleviate symptoms by increasing DA to normal levels. This hypodopaminergic view on PTSD suggests that the cooccurrence of drug addiction and alcohol abuse often observed in PTSD patients may in fact be a coping (selfmedication-like) response to compensate for abnormally low levels of DA. Altogether, our results suggest that VTA dopaminergic neurons may be key in understanding the onset and symptomatology of PTSD, and that drugs specifically targeted to the dopaminergic system may be of interest for the prevention and treatment of PTSD.

\section{ACKNOWLEDGEMENTS}

We would like to thank Stephen Brookshire, Julia Cremer, and Chu Qin for their technical assistance, Tally LargentMilnes and Beatriz Fiorivanti for their helpful comments and training, Dr Todd Vanderah for the use of space and technical assistance, and Dr Jose Valdés for all the helpful comments. This work was supported in part by CONACyT (NSCF) and NSF grant CRCNS 1010172 (J-MF).

\section{DISCLOSURE}

The authors declare no conflict of interest.

\section{REFERENCES}

Anstrom KK, Miczek KA, Budygin EA (2009). Increased phasic dopamine signaling in the mesolimbic pathway during social defeat in rats. Neuroscience 161: 3-12.

Anstrom KK, Woodward DJ (2005). Restraint increases dopaminergic burst firing in awake rats. Neuropsychopharmacology 30: $1832-1840$.

Apud JA, Mattay V, Chen J, Kolachana BS, Callicott JH, Rasetti R et al (2007). Tolcapone improves cognition and cortical information processing in normal human subjects. Neuropsychopharmacology 32: 1011-1020.

Asmundson GJ, Coons MJ, Taylor S, Katz J (2002). PTSD and the experience of pain: research and clinical implications of shared vulnerability and mutual maintenance models. Can J Psychiatry 47: 930-937.

Asmundson GJ, Katz J (2009). Understanding the co-occurrence of anxiety disorders and chronic pain: state-of-the-art. Depress Anxiety 26: 888-901.

Becerra L, Breiter HC, Wise R, Gonzalez RG, Borsook D (2001). Reward circuitry activation by noxious thermal stimuli. Neuron 32: 927-946. 
Borsook D, Becerra L, Carlezon WA Jr., Shaw M, Renshaw P, Elman I et al (2007). Reward-aversion circuitry in analgesia and pain: implications for psychiatric disorders. Eur J Pain 11: $7-20$.

Brischoux F, Chakraborty S, Brierley DI, Ungless MA (2009). Phasic excitation of dopamine neurons in ventral VTA by noxious stimuli. Proc Natl Acad Sci USA 106: 4894-4899.

Cao JL, Covington HE 3rd, Friedman AK, Wilkinson MB, Walsh JJ, Cooper DC et al (2010). Mesolimbic dopamine neurons in the brain reward circuit mediate susceptibility to social defeat and antidepressant action. J Neurosci 30: 16453-16458.

Chaouloff F, Durand M, Mormede P (1997). Anxiety-and activityrelated effects of diazepam and chlordiazepoxide in the rat light/ dark and dark/light tests. Behav Brain Res 85: 27-35.

Cooper DC (2002). The significance of action potential bursting in the brain reward circuit. Neurochem Int 41: 333-340.

Corral-Frías N, Brookshire S, Edelman-Vogelsang K, Valdés J, Fellous J, French E (2010): Efectos del estrés traumático en ratas: estudios conductuales, farmacológicos y electrofisiológicos Vigésimo Congreso de la Sociedad Mexicana del Análisis de la Conducta: Oaxtepec, Morelos, México.

Costall B, Jones BJ, Kelly ME, Naylor RJ, Tomkins DM (1989). Exploration of mice in a black and white test box: validation as a model of anxiety. Pharmacol Biochem Behav 32: 777-785.

Elman I, Lowen S, Frederick BB, Chi W, Becerra L, Pitman RK (2009). Functional neuroimaging of reward circuitry responsivity to monetary gains and losses in posttraumatic stress disorder. Biol Psychiatry 66: 1083-1090.

Ennaceur A, Michalikova S, Chazot PL (2006). Models of anxiety: responses of rats to novelty in an open space and an enclosed space. Behav Brain Res 171: 26-49.

Fields HL, Hjelmstad GO, Margolis EB, Nicola SM (2007). Ventral tegmental area neurons in learned appetitive behavior and positive reinforcement. Annu Rev Neurosci 30: 289-316.

Frayne SM, Chiu VY, Iqbal S, Berg EA, Laungani KJ, Cronkite RC et al (2011). Medical care needs of returning veterans with PTSD: their other burden. J Gen Intern Med 26: 33-39.

Frey U, Schroeder H, Matthies H (1990). Dopaminergic antagonists prevent long-term maintenance of posttetanic LTP in the CA1 region of rat hippocampal slices. Brain Res 522: 69-75.

Garcia R, Vouimba RM, Baudry M, Thompson RF (1999). The amygdala modulates prefrontal cortex activity relative to conditioned fear. Nature 402: 294-296.

Geerse GJ, van Gurp LC, Wiegant VM, Stam R (2006). Individual reactivity to the open-field predicts the expression of stressinduced behavioural and somatic pain sensitisation. Behav Brain Res 174: 112-118.

Goto Y, Grace AA (2006). Alterations in medial prefrontal cortical activity and plasticity in rats with disruption of cortical development. Biol Psychiatry 60: 1259-1267.

Goto Y, Otani S, Grace AA (2007). The Yin and Yang of dopamine release: a new perspective. Neuropharmacology 53: 583-587.

Grace AA, Bunney BS (1984). The control of firing pattern in nigral dopamine neurons: burst firing. J Neurosci 4: 2877-2890.

Gresch PJ, Sved AF, Zigmond MJ, Finlay JM (1994). Stress-induced sensitization of dopamine and norepinephrine efflux in medial prefrontal cortex of the rat. J Neurochem 63: 575-583.

Hopper JW, Pitman RK, Su Z, Heyman GM, Lasko NB, Macklin ML et al (2008). Probing reward function in posttraumatic stress disorder: expectancy and satisfaction with monetary gains and losses. J Psychiatr Res 42: 802-807.

Houlihan DJ (2011). Psychostimulant treatment of combat-related posttraumatic stress disorder. J Psychopharmacol 25: 1568-1572.

Inoue T, Izumi T, Maki Y, Muraki I, Koyama T (2000). Effect of the dopamine $\mathrm{D}(1 / 5)$ antagonist $\mathrm{SCH} 23390$ on the acquisition of conditioned fear. Pharmacol Biochem Behav 66: $573-578$
Kallai J, Makany T, Csatho A, Karadi K, Horvath D, Kovacs-Labadi $B$ et al (2007). Cognitive and affective aspects of thigmotaxis strategy in humans. Behav Neurosci 121: 21-30.

Kessler RC, Berglund P, Demler O, Jin R, Merikangas KR, Walters EE (2005). Lifetime prevalence and age-of-onset distributions of DSM-IV disorders in the National Comorbidity Survey Replication. Arch Gen Psychiatry 62: 593-602.

Kessler RC, Sonnega A, Bromet E, Hughes M, Nelson CB (1995). Posttraumatic stress disorder in the National Comorbidity Survey. Arch Gen Psychiatry 52: 1048-1060.

Kofoed L, Friedman MJ, Peck R (1993). Alcoholism and drug abuse in patients with PTSD. Psychiatr Q 64: 151-171.

Krishnan V, Han MH, Graham DL, Berton O, Renthal W, Russo SJ et al (2007). Molecular adaptations underlying susceptibility and resistance to social defeat in brain reward regions. Cell 131: 391-404.

Langevin JP, De Salles AA, Kosoyan HP, Krahl SE (2010). Deep brain stimulation of the amygdala alleviates post-traumatic stress disorder symptoms in a rat model. J Psychiatr Res 44: 1241-1245.

Liberzon I, Sripada CS (2008). The functional neuroanatomy of PTSD: a critical review. Prog Brain Res 167: 151-169.

Liberzon I, Taylor SF, Amdur R, Jung TD, Chamberlain KR, Minoshima $S$ et al (1999). Brain activation in PTSD in response to trauma-related stimuli. Biol Psychiatry 45: 817-826.

Lisman J, Grace AA, Duzel E (2011). A neoHebbian framework for episodic memory; role of dopamine-dependent late LTP. Trends Neurosci 34: 536-547.

Lisman JE, Grace AA (2005). The hippocampal-VTA loop: controlling the entry of information into long-term memory. Neuron 46: 703-713.

Louvart H, Maccari S, Ducrocq F, Thomas P, Darnaudery M (2005). Long-term behavioural alterations in female rats after a single intense footshock followed by situational reminders. Psychoneuroendocrinology 30: 316-324.

Mahmoodi M, Shahidi S, Hasanein P (2011). Involvement of the ventral tegmental area in the inhibitory avoidance memory in rats. Physiol Behav 102: 542-547.

Mikics E, Baranyi J, Haller J (2008). Rats exposed to traumatic stress bury unfamiliar objects-a novel measure of hypervigilance in PTSD models? Physiol Behav 94: 341-348.

Moaddab M, Haghparast A, Hassanpour-Ezatti M (2009). Effects of reversible inactivation of the ventral tegmental area on the acquisition and expression of morphine-induced conditioned place preference in the rat. Behav Brain Res 198: 466-471.

Moore H, Rose HJ, Grace AA (2001). Chronic cold stress reduces the spontaneous activity of ventral tegmental dopamine neurons. Neuropsychopharmacology 24: 410-419.

Morris RG, Moser EI, Riedel G, Martin SJ, Sandin J, Day M et al (2003). Elements of a neurobiological theory of the hippocampus: the role of activity-dependent synaptic plasticity in memory. Philos Trans R Soc Lond B Biol Sci 358: 773-786.

Morrow BA, Redmond AJ, Roth RH, Elsworth JD (2000). The predator odor, TMT, displays a unique, stress-like pattern of dopaminergic and endocrinological activation in the rat. Brain Res 864: 146-151.

Nair-Roberts RG, Chatelain-Badie SD, Benson E, White-Cooper H, Bolam JP, Ungless MA (2008). Stereological estimates of dopaminergic, GABAergic and glutamatergic neurons in the ventral tegmental area, substantia nigra and retrorubral field in the rat. Neuroscience 152: 1024-1031.

Najavits LM, Weiss RD, Shaw SR (1997). The link between substance abuse and posttraumatic stress disorder in women. A research review. Am J Addict 6: 273-283.

Ohl F (2003). Testing for anxiety. Clin Neurosci Res 3: 233-238.

Payne JD, Jackson ED, Hoscheidt S, Ryan L, Jacobs WJ, Nadel L (2007). Stress administered prior to encoding impairs neutral but enhances emotional long-term episodic memories. Learn Mem 14: 861-868. 
Payne JD, Nadel L, Britton WB, Jacobs WJ (eds) (2003). The Biopsychology of Trauma and Memory in Humans. Oxford University Press: New York.

Pellow S (1985). Can drug effects on anxiety and convulsions be separated? Neurosci Biobehav Rev 9: 55-73.

Pellow S, Chopin P, File SE, Briley M (1985). Validation of open:closed arm entries in an elevated plus-maze as a measure of anxiety in the rat. J Neurosci Methods 14: 149-167.

Pezze MA, Feldon J (2004). Mesolimbic dopaminergic pathways in fear conditioning. Prog Neurobiol 74: 301-320.

Pfeiffer UJ, Fendt M (2006). Prefrontal dopamine D4 receptors are involved in encoding fear extinction. Neuroreport 17: 847-850.

Pissiota A, Frans O, Fernandez M, von Knorring L, Fischer H, Fredrikson M (2002). Neurofunctional correlates of posttraumatic stress disorder: a PET symptom provocation study. Eur Arch Psychiatry Clin Neurosci 252: 68-75.

Pynoos RS, Ritzmann RF, Steinberg AM, Goenjian A, Prisecaru I (1996). A behavioral animal model of posttraumatic stress disorder featuring repeated exposure to situational reminders. Biol Psychiatry 39: 129-134.

Rauch SL, Shin LM, Phelps EA (2006). Neurocircuitry models of posttraumatic stress disorder and extinction: human neuroimaging research-past, present, and future. Biol Psychiatry 60: 376-382.

Saade NE, Atweh SF, Bahuth NB, Jabbur SJ (1997). Augmentation of nociceptive reflexes and chronic deafferentation pain by chemical lesions of either dopaminergic terminals or midbrain dopaminergic neurons. Brain Res 751: 1-12.

Seip KM, Morrell JI (2009). Transient inactivation of the ventral tegmental area selectively disrupts the expression of conditioned place preference for pup-but not cocaine-paired contexts. Behav Neurosci 123: 1325-1338.

Shin LM, Shin PS, Heckers S, Krangel TS, Macklin ML, Orr SP et al (2004). Hippocampal function in posttraumatic stress disorder. Hippocampus 14: 292-300.
Siegmund A, Wotjak CT (2006). Toward an animal model of posttraumatic stress disorder. Ann N Y Acad Sci 1071: 324-334.

Sigurdsson T, Doyere V, Cain CK, LeDoux JE (2007). Long-term potentiation in the amygdala: a cellular mechanism of fear learning and memory. Neuropharmacology 52: 215-227.

Stam R (2007). PTSD and stress sensitisation: a tale of brain and body Part 2: animal models. Neurosci Biobehav Rev 31: 558-584.

Stam R, van Laar TJ, Akkermans LM, Wiegant VM (2002). Variability factors in the expression of stress-induced behavioural sensitisation. Behav Brain Res 132: 69-76.

Tan KR, Yvon C, Turiault M, Mirzabekov JJ, Doehner J, Labouebe $\mathrm{G}$ et al (2012). GABA neurons of the VTA drive conditioned place aversion. Neuron 73: 1173-1183.

Treit D, Fundytus M (1988). Thigmotaxis as a test for anxiolytic activity in rats. Pharmacol Biochem Behav 31: 959-962.

Ungless MA, Grace AA (2012). Are you or aren't you? Challenges associated with physiologically identifying dopamine neurons Trends Neurosci.

Valenti O, Lodge DJ, Grace AA (2011). Aversive stimuli alter ventral tegmental area dopamine neuron activity via a common action in the ventral hippocampus. J Neurosci 31: 4280-4289.

Van Dijken HH, Van der Heyden JA, Mos J, Tilders FJ (1992). Inescapable footshocks induce progressive and long-lasting behavioural changes in male rats. Physiol Behav 51: 787-794.

Walf AA, Frye CA (2007). The use of the elevated plus maze as an assay of anxiety-related behavior in rodents. Nat Protoc 2: 322-328.

Yehuda R, Antelman SM (1993). Criteria for rationally evaluating animal models of posttraumatic stress disorder. Biol Psychiatry 33: 479-486.

Yehuda R, LeDoux J (2007). Response variation following trauma: a translational neuroscience approach to understanding PTSD. Neuron 56: 19-32.

Supplementary Information accompanies the paper on the Neuropsychopharmacology website (http://www.nature.com/npp) 